\title{
Pain, pain, go away: The importance of measuring patient-reported outcomes
}

\author{
Benjamin D. Kozower, MD, MPH
}

From the Washington University School of Medicine, St Louis, Mo.

Disclosures: Author has nothing to disclose with regard to commercial support.

Received for publication Feb 25, 2017; accepted for publication March 3, 2017; available ahead of print April 5, 2017.

Address for reprints: Benjamin D. Kozower, MD, MPH, Washington University, School of Medicine, Division of Cardiothoracic Surgery, One Barnes-Jewish Hospital Plaza, Suite 3108 Queeny Tower, St Louis, MO 63110 (E-mail: kozowerb@wudosis.wustl.edu).

J Thorac Cardiovasc Surg 2017;154:660

$0022-5223 / \$ 36.00$

Copyright $(2) 2017$ by The American Association for Thoracic Surgery

http://dx.doi.org/10.1016/j.jtcvs.2017.03.031

Lin and colleagues ${ }^{1}$ are to be congratulated for their effort to study patient-reported outcomes (PROs) beyond the typical 30-day surgical window. In their article "Evaluation of Acute and Chronic Pain Outcomes After Robotic, VATS, or Open Anatomic Pulmonary Resection," the authors measured acute and chronic pain scores from 498 patients over a 5-year period. They concluded that minimally invasive approaches resulted in less acute pain and chronic numbness and found no significant differences between thoracoscopy and robotic minimally invasive approaches.

The American College of Chest Physicians guidelines recommend that patients undergoing curative-intent surgical resection for non-small cell lung cancer should be evaluated with a validated health-related quality-of-life instrument at baseline and at follow-up clinic visits. ${ }^{2}$ However, the routine collection of longitudinal health-related quality of life measures or PROs has not become a widely implemented part of routine clinical care. ${ }^{3}$ The 3 major barriers to capturing longitudinal PRO measurement are technologic, financial, and a lack of standardized methods for integrating PRO into routine work flow.

The US National Institutes of Health funded the development of a comprehensive standardized collection of health assessment tools for the measurement of physical, mental, and social function domains, known as the "Patient Reported Outcomes Measurement Information System" (PROMIS). ${ }^{4}$ The PROMIS assessments are recommended for use in PROs in adult oncology, along with several other selected instruments. The PROMIS assessments are validated assessment tools developed for broad use across populations with disease. The electronic collection of PROMIS assessment data also is directly facilitated through a webbased resource that supports administering, scoring, and storing assessment results.

This study by Lin and colleagues ${ }^{1}$ demonstrates some of the critical challenges and opportunities for incorporating PRO measures into thoracic surgery care. Although the authors measured short-term pain scores on 498 patients, they were only successful in capturing the longitudinal data,

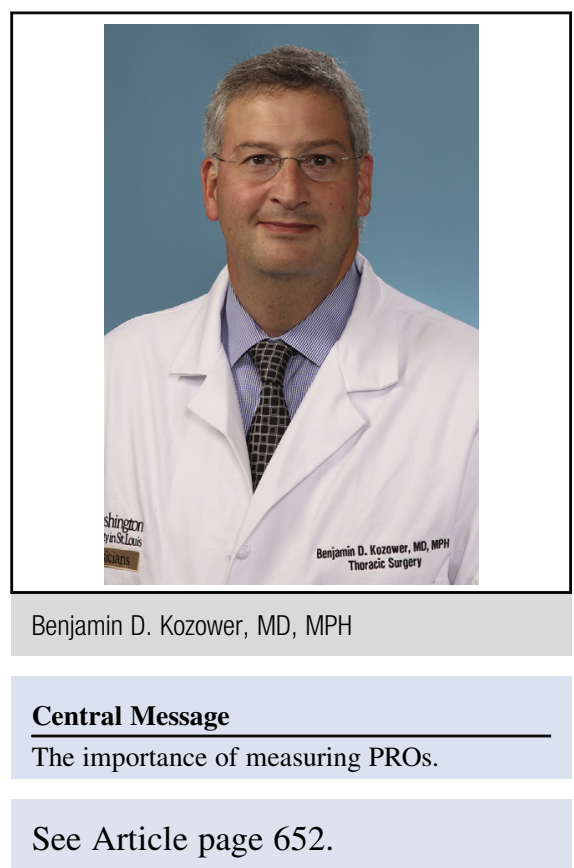

chronic pain, on 169 patients (34\% of the study population). These data are required to truly compare one surgical approach with another, as well as surgical versus nonsurgical treatments for lung cancer. PROMIS has an instrument to measure pain interference for patients with cancer along with instruments for global health, functional status, dyspnea, and more than 100 other assessments. ${ }^{4}$ However, incorporating the collection of these assessments into routine care will require significant investments in information technology support for electronic medical records and addressing the other key barriers that have limited widespread adoption. Thoracic surgeons need to understand that PROs are likely to be an increasingly important part of the value equation, and they need to be prepared to work with their specialty societies and hospital leadership to improve the capture of PRO data into routine workflow.

\section{References}

1. Kwon ST, Zhao L, Reddy RM, Chang AC, Orringer MB, Brummett CM, et al. Evaluation of acute and chronic pain outcomes after robotic, VATS, or open anatomic pulmonary resection. J Thorac Cardiovasc Surg. 2017;154:652-9.

2. Colt HG, Murgu SD, Korst RJ, Slatore CG, Unger M, Quadrelli S. Follow-up and surveillance of the patient with lung cancer after curative-intent therapy. Chest. 2013;143(5 Suppl):e437S-454.

3. Basch E. Patient-reported outcomes - harnessing patients' voices to improve clinical care. N Engl J Med. 2017;376:105-8.

4. PROMIS Assessment Center. Available at: https://www.assessmentcenter.net/ Default.aspx. Accessed February 25, 2017. 